LICENÇA CC BY:

Artigo distribuído sob os termos

Creative Commons, permite uso e distribuição irrestrita em qualquer meio desde que o autor credite a fonte original.

\title{
GOVERNANÇA EM REDE E PARCERIAS PÚBLICO-PRIVADAS EM EDUCAÇÃO NO ESTADO DO RS
}

NETWORK GOVERNANCE AND PUBLIC-PRIVATE PARTNERSHIPS IN EDUCATION IN THE STATE OF RIO GRANDE DO SUL GOBERNANZA EN RED Y ASOCIACIONES PÚBLICA-PRIVADAS EN EDUCACIÓN EN EL ESTADO DE RS

Maria de Fátima Cóssio ${ }^{1}$

Susana Schneid Scherer ${ }^{2}$

${ }^{1}$ Doutora em Educação pela UFRGS. Docente do Programa de Pós-Gradação em Educação da Universidade Federal de Pelotas (UFPEL), Pelotas, RS, Brasil.

${ }^{2}$ Doutoranda em Educação pela Universidade Federal de Pelotas (UFPEL), Pelotas, RS, Brasil.

Resumo: Este artigo aborda dados parciais da pesquisa em desenvolvimento pelo NEPPE/ UFPEL ${ }^{1}$, cujo objetivo é analisar os possíveis efeitos das parcerias público-privadas nos sistemas públicos de educação no Estado do Rio Grande do Sul (RS). Para tanto, aprofundaram-se os conceitos de Nova Gestão Pública (NGP) e de Governança, entendendo-os como centrais para a compreensão do cenário em que se instauram e proliferam as PPPs e as redes de políticas educacionais. A pesquisa utiliza uma abordagem qualitativa e a metodologia de etnografia de rede de Stephen Ball (2014) na coleta dos dados. Inicialmente, realizou-se o mapeamento das instituições privadas que, de forma mais recorrente, atuam nos sistemas públicos. Desse levantamento, foram evidenciadas cinco instituições: Instituto Ayrton Senna (IAS), Instituto Natura, Sistema de Crédito Cooperativo (SICREDI), Associação dos Fumicultores do Brasil (AFUBRA) e Federação Nacional das Associações Atléticas do Banco do Brasil (FENABB). Após localizar os principais parceiros de cada ente, adaptaram-se as propriedades de rede, sugeridas por Tichy e colaboradores (1979), e citadas por Lopes e Baldi (2009), buscando contemplar a diversidade de esferas dessas relações e a natureza das ligações, observando questões de conteúdo, intensidade, reciprocidade, clareza, multiplexidade; e características estruturais, como tamanho, densidade, clustering e centralidade. As análises das redes permitiram identificar as relações entre os parceiros e visualizar algumas aproximações com relação às propostas de cada um destes entes atuantes na educação do Estado do RS.

Palavras-chave: Governança em rede; Políticas educacionais; Parcerias público-privadas; Educação no Estado do Rio Grande do Sul.

Abstract: This article addresses partial data from a study currently underway at the NEPPE/ UFPEL, which aims to analyze the possible effects of public-private partnerships (PPP) in public education systems in the State of Rio Grande do Sul. It analyzes the concepts of New Public Management (NPM) and Governance, as these are seen as central to understanding the scenario 
in which PPP and networks in education policies are established and proliferated. This research uses the qualitative approach and Stephen Ball's (2014) network ethnography method for the data collection. Initially, a mapping was carried out of private institutions that regularly work in the public systems. Based on this survey, five institutions were identified: Instituto Ayrton Senna Institute (IAS), Instituto Natura (Natura Institute), Sistema de Crédito Cooperativo (SICREDI) (Cooperative Credit System), the Brazilian Tobacco Growers' Association (AFUBRA), and the National Federation of Athletic Associations of Banco do Brazil (FENABB). Next, the main partners of each entity were localized, adapting the network properties, suggested by Tichy et al. (1979), and cited by Lopes and Baldi (2009), seeking to contemplate the diversity of spheres in these relationships and the nature of the connections, observing questions of content, intensity, reciprocity, clarity, multiplicity; and structural characteristics such as size, density, clustering and centrality. The analysis of the entities and their networks enabled us to identify the relationships between the partners, and to visualize some similarities in the proposals of each of these entities, that operate in the public education of the State of Rio Grande do Sul.

Keywords: Network governance; Educational policies; Public-Private Partnerships; Education in the State of Rio Grande do Sul/Brazil.

Resumen: Este artículo aborda datos parciales de la investigación en desarrollo por el NEPPE/ UFPEL, cuyo objetivo central es analizar los posibles efectos de las asociaciones públicaprivadas en los sistemas públicos de educación en el Estado de Rio Grande do Sul (RS). Para ello, se profundizaron los conceptos de Nueva Gestión Pública (NGP) y de Gobernanza, entendiéndolos como centrales para la comprensión del escenario en que se instaura y proliferan estas asociaciones pública-privadas y las redes de políticas educacionales. La investigación utiliza un enfoque cualitativo y la metodología de etnografía de red de Stephen Ball (2014) en la recolección de datos. Inicialmente se realizó el mapeo de las instituciones privadas que, de forma más recurrente, actúan en los sistemas públicos de educación. De esto se evidenció cinco instituciones: Instituto Ayrton Senna (IAS), Instituto Natura, Sistema de Crédito Cooperativo (SICREDI), Associação dos Fumicultores do Brasil (AFUBRA) y Federação Nacional das Associações Atléticas do Banco do Brasil (FENABB). Después de ubicar a los principales socios de cada ente, se adaptaron a las propiedades de red, sugeridas por Tichy y colaboradores (1979), y citadas por Lopes y Baldi (2009), buscando contemplar la diversidad de esferas de esas redes las relaciones y la naturaleza de las conexiones, observando cuestiones de contenido, intensidad, reciprocidad, claridad, multiplexidad; y características estructurales como tamaño, densidad, clustering y centralidad. Los análisis de las redes permitieron identificar las relaciones entre los socios y visualizar algunas aproximaciones con respecto a las propuestas de cada uno de estos expresivos entes actuantes en las redes públicas de educación en el Estado de RS.

Palabras-clave: Gobernanza en red; Políticas educativas; Asociaciones Pública-Privadas; Educación en el Estado de Rio Grande do Sul/Brasil.

\section{Introdução}

Este artigo trata de uma pesquisa em desenvolvimento desde 2016 pelo Núcleo de Estudos e Pesquisas em Políticas Públicas Educacionais (NEPPE) da Universidade Federal de Pelotas (UFPEL) que objetivou, inicialmente, identificar quais as instituições privadas, com ou sem fins lucrativos, que atuam de forma recorrente nas escolas e nos 
sistemas públicos (redes de escolas) do Estado do Rio Grande do Sul (RS), por meio de Parcerias Público-Privadas (PPPs). Após a identificação das instituições, esta pesquisa visou aprofundar o estudo sobre cada uma delas, buscando os parceiros que possam indicar a existência de redes políticas atuando na educação pública.

Reconhecemos que as PPPs manifestam novas relações que se estabelecem entre Estado, mercado e sociedade civil, especialmente por meio da concepção de governança que propicia a constituição de redes de transferência e influências políticas (CÓSSIO, 2015), e que têm na Nova Gestão Pública (NGP) ou no Gerencialismo suas bases (NEWMAN; CLARKE, 2012). Dessa maneira, estes conceitos são fundamentais, pois explicitam novas formas de organização e atuação dos setores públicos que têm repercussões na configuração e na materialidade das políticas educacionais, notadamente a partir da constituição de redes políticas que se organizam em torno e sobre as instituições públicas, tendo implicações na educação escolar.

No caso das Parcerias Público-Privadas em Educação (PPPEs), elas envolvem, em geral, os sistemas escolares com propostas elaboradas por segmentos desvinculados da área educacional, os quais "em nome de uma maior competência técnica substituem o compromisso político da gestão pública com a elaboração e o acompanhamento das políticas educacionais" (ROBERTSON; VERGER, 2012, p.111), e passam a atuar em diferentes espaços da educação, da gestão, da organização, da formação docente, da avaliação, da criação de currículos, etc.

Os estudos na área de políticas educacionais evidenciam a presença desse tipo de relação, especialmente a partir da década de 1990, sobretudo na Inglaterra (ROBERTSON; VERGER, 2012; ROBERTSON, 2012;), assim como no Brasil (PERONI, 2013b; 2015). Outras pesquisas têm explorado o conceito de redes de políticas (BALL, 2014) ou redes de governança (SHIROMA, 2016) para exprimir as articulações em teia que são constituídas pelas diferentes formas de atuação ou de criação de oportunidades para o setor privado na educação pública.

Assim, este estudo se propõe a aprofundar a compreensão das PPPEs por meio da investigação dos entes privados que atuam no setor público educacional do Estado do RS. Pretendemos problematizar as novas relações que se estabelecem entre Estado, Mercado e Sociedade Civil, por meio da NGP, do gerencialismo e da governança; adensar o entendimento sobre redes de políticas, transferência de políticas e influências; apreender os princípios e as intencionalidades das PPPEs, a partir do conhecimento das instituições prevalecentes nos sistemas educativos municipais e estadual do RS; e, por fim, analisar as implicações das PPPEs para a educação no Estado. 


\section{Nova gestão pública (NGP), governança e PPPs: algumas conceituações.}

Os conceitos de NGP e de governança são importantes para a compreensão e análise crítica do fenômeno crescente das PPPs, sobretudo em educação.

A legislação brasileira, desde 2004, regulamenta e promove segurança jurídica às parcerias que, por si só, não podem ser vistas como negativas ao setor público. O que está em causa na presente pesquisa são as formas de parceria que retiram do Estado a prerrogativa de definir os fins e os objetivos da educação pública, na medida em que, em vários casos, transfere para a esfera privada a competência na elaboração de currículos, materiais pedagógicos, formação de professores e gestão escolar, alterando os sentidos públicos, laicos, baseados no pluralismo de ideias e concepções que permitem às escolas propiciar o pensamento crítico e a ampliação cultural, constitucionalmente definidos para a educação básica brasileira, ofertada igualmente para todos, que só poderá ser garantida sob a responsabilidade do Estado.

No contexto brasileiro, desde os anos 1990, com a introdução de perspectivas teóricas e neoliberais e, por meio do advento da globalização da economia, criaram-se as condições propícias para as transformações no papel e no tamanho do Estado, com o propósito de atender à lógica, proposta externamente, de modernização da máquina pública e de suas relações com outras nações, com a sociedade civil e com o mercado.

O discurso predominante era o de ineficiência do Estado e, portanto, dos serviços públicos prestados pelos órgãos de governo, acompanhado da ideia de redução de gastos, considerando a crise fiscal vivenciada pelos países desenvolvidos, notadamente nos Estados Unidos nos anos 1970. O diagnóstico da crise à época assinalava para os gastos excessivos do Estado com as políticas sociais, sendo que a solução deveria passar, necessariamente, pela redução do seu tamanho (cargos, encargos, recursos), além de alterar as suas formas de atuação (gestão), inserindo no setor princípios e práticas da gestão empresarial.

A perspectiva de redução do tamanho do Estado, propugnada e disseminada amplamente pelo neoliberalismo, atingiu o Brasil, de forma mais incisiva, por meio do Plano Diretor de Reforma da Administração do Estado (PDRAE), que sustentou o Ministério da Administração Federal e a Reforma do Estado (MARE), sob a gestão de Luiz Carlos Bresser Pereira, em 1995. O MARE foi criado exclusivamente para administrar o PDRAE e perdurou durante o primeiro mandato do Presidente Fernando Henrique Cardoso (FHC) e depois foi extinto, sendo que a reforma do Estado passou a ser de responsabilidade do Ministério do Planejamento e Gestão.

O PDRAE objetivou contribuir na construção de um aparelho de Estado forte e eficiente, o que compreendeu três dimensões (BRESSER PEREIRA, 1997): a) uma dimensão institucional-legal, voltada à descentralização da estrutura organizacional 
do aparelho do Estado por meio da criação de novos formatos organizacionais, como as agências executivas, regulatórias, e as organizações sociais; b) uma dimensão de gestão, definida pela maior autonomia e a introdução de três novas formas de responsabilização dos gestores - a administração por resultados, a competição administrada por excelência e o controle social - em substituição parcial dos regulamentos rígidos, da supervisão e da auditoria, que caracterizam a administração burocrática; e c) uma dimensão cultural, de mudança de mentalidade, visando passar da desconfiança generalizada que caracteriza a administração burocrática para uma confiança maior, ainda que limitada, própria da administração gerencial.

Um dos princípios fundamentais deste projeto de reforma é o de que o Estado, embora conservando parte de sua ação na área social, só deve executar diretamente as tarefas que Ihes são exclusivas, que envolvem o emprego do poder de Estado, ou que apliquem os recursos do Estado. Entre as tarefas exclusivas de Estado devem-se distinguir as tarefas centralizadas de formulação e controle das políticas públicas e da lei a serem executadas por secretarias ou departamentos do Estado, das tarefas de execução, que devem ser descentralizadas para agências executivas e agências reguladoras autônomas. Todos os demais serviços que a sociedade decide prover com os recursos dos impostos não devem ser realizados no âmbito da organização do Estado, por servidores públicos, mas devem ser contratados com terceiros (terceirização). Os serviços sociais e científicos, para os quais os mercados não apresentam aderência e vocação, devem ser contratados com organizações públicas não estatais de serviço, as 'organizações sociais', enquanto que os demais podem ser contratados com empresas privadas. As três formas gerenciais de controle - controle social, controle de resultados e competição administrada - devem ser aplicadas tanto às agências, quanto às organizações sociais.

Os três princípios norteadores da reforma do Estado (institucional, cultural e gerencial) foram levados a cabo nos anos subsequentes da gestão $\mathrm{FHC}$, que perdurou até 2002, sempre com a proclamada superação da perspectiva burocrática, visando conferir aos órgãos de governo maior eficácia e eficiência.

De acordo com Bresser Pereira (1997), toda sociedade, para se coordenar, usa um conjunto de mecanismos de controle ou de coordenação que pode ser organizado e classificado de muitas maneiras. Destaca, assim, na perspectiva institucional, os três mecanismos de controle que considera fundamentais: o Estado, o mercado e a sociedade civil. Parte da consideração de que podemos utilizar, em vez do institucional, o critério funcional. Segundo esse critério, há também três formas de controle: o controle hierárquico ou administrativo, que é exercido dentro das organizações públicas ou privadas; o controle democrático ou social, que ocorre em termos políticos sobre as organizações e os indivíduos; e o controle econômico, que acontece pela via do mercado. Este segundo critério é talvez mais geral e permite compreender melhor o espaço que cabe aos mecanismos institucionais no escopo da relação Estado, mercado e sociedade civil. 
Considerando o critério funcional, Bresser Pereira (1997) destaca os seguintes mecanismos de controle, além do sistema jurídico que antecede a todos: (1) mercado, (2) controle social (democracia direta), (3) controle democrático representativo, (4) controle hierárquico gerencial, (5) controle hierárquico burocrático e (6) controle hierárquico tradicional. Na prática de gestão, esses mecanismos ocorrem de forma combinada. No entanto, no contexto de globalização neoliberal, predominam os mecanismos de mercado e o controle hierárquico gerencial.

A perspectiva de gestão gerencial se relaciona à ideia de Nova Gestão Pública (NGP) que, tendo o intuito de superar a gestão burocrática weberiana, considerada ineficaz, adota princípios e práticas típicas de empresas no interior da máquina pública, como resposta às direções pós-crise de 1970. Refere-se a uma gestão por resultados a qual valoriza o produto do trabalho (quantidade), e menos o processo (qualidade), desencadeando mudanças internas substanciais, embora se observem práticas híbridas.

Nesse sentido, no Brasil, foram desencadeados diversos e diferentes movimentos de terceirização do serviço público, privatizações, incentivo ao comunitarismo e à criação de duas novas figuras políticas: as Organizações Sociais (OS) e as Organizações da Sociedade Civil de Interesse Público (OSCIP), normatizadas juridicamente pelas Leis 9.637/1998 e 9.790/1999, respectivamente. É necessário destacar que a ênfase na sociedade civil, no cenário de afastamento do Estado, cria uma noção de maior participação dos diferentes segmentos da sociedade, de democratização das relações sociais e de controle público. Tal ideia está alicerçada no modelo da Terceira Via.

A Terceira Via ou nova social-democracia constituiu a base teórica pela qual foi assentada a proposta de reforma do Estado brasileiro. Sua origem pode ser evidenciada na Inglaterra, como proposta de governo de Tony Blair, tendo como seu principal teórico o reconhecido sociólogo Antony Giddens. Grosso modo, a Terceira Via, como o próprio nome indica, se propõe a ser uma alternativa ao neoliberalismo ortodoxo, vivenciado pelo Reino Unido durante os anos de governo de Margareth Thatcher, e a social democracia fortemente efetivada nos países centrais.

A base de sustentação do projeto encabeçado por Blair é justamente a reforma do Estado, a criação de mecanismos de controle e as parcerias público-privadas, com o slogan de que "todos" perseguiriam os mesmos propósitos: o bem comum. Peroni (2013a, p. 238-239) considera que a Terceira Via pode assumir diferentes formas, mas tem como pontos em comum:

A reforma do governo e do Estado; o papel regulador do Estado no mercado e na sociedade civil; papel
central da sociedade civil, identificada com o empreendedorismo; novo contrato social, vinculando
direitos a responsabilidades; redefinição do conceito de igualitarismo; as relações entre o público e o
privado nas políticas educacionais no contexto da terceira via baseado no investimento em habilidades
e capacidades individuais; criação de uma economia dinâmica, com parcerias entre o governo e a
sociedade civil; a conexão entre políticas sociais e econômicas e o questionamento aos direitos sociais e
trabalhistas; Estado de Bem-Estar sustentável com equilíbrio entre direitos e sustentabilidade; políticas
ativas para combater o crime; política ecológica; capitalismo responsável, as empresas devem assumir
obrigações sociais e que deve haver uma regulamentação nacional e internacional para as corporações. 
De forma geral, a Terceira Via se apresenta como um Welfare positivo, um tipo de capitalismo menos excludente, o qual contesta os excessos do neoliberalismo lançando, entre outras ideias relacionadas a uma maior flexibilização do Estado, a concretização de políticas públicas em associação a atores paraestatais (CÓSSIO, 2015). Por meio disso, é visada à atenuação causada pelo modelo capitalista neoliberal, o qual formou uma rede de miseráveis que não contribui nem mesmo para a manutenção da lógica do capital. Projeta-se a reconfiguração do metabolismo capitalista a partir da inserção da lógica do mercado por dentro do Estado, pelo fomento de relações do Estado com a sociedade civil. Dentro desta relação, o Terceiro Setor ${ }^{2}$, como membro privado não lucrativo, constitui-se como uma organização da sociedade e ganha espaço para atuar junto ao Estado na prestação de serviços ligados aos mais diversos setores, entre os quais a educação, influenciando na configuração das políticas públicas.

É possível dizer que a Terceira Via, com os princípios da governança e da NGP/ gerencialismo, no contexto da globalização neoliberal contemporânea, cria as condições objetivas para a efetivação (legal e prática) das PPPs.

Robertson e Verger (2012) compartilham desta ideia, dizendo que

O renascimento das "parcerias" também se articulou a mudanças mais amplas na paisagem ideológica e conceitual da governança, em direção a uma "terceira via" entre o Estado e o mercado, como a de Blair, em seu "governo para a modernização" no Reino Unido (Newman, 2001). Elas foram um corretivo para a presença demasiada do Estado (keynesianismo), por um lado, e a ausência dele, por outro (privatização). Ao agir como uma ponte entre cada setor, as parcerias atuavam como um canal, permitindo o aproveitamento de valores de cada parceiro, a serem capitalizados no futuro (p.1139).

Para Shiroma e Evangelista (2014), a perspectiva de NGP, assumida no âmbito do projeto da Terceira Via, representa um esforço da elite empresarial para maximizar seus benefícios. O próprio economicista chefe do Banco Mundial John Williamson preludiou, no final dos anos 1990, a ideia de se trabalhar em direção a um "Consenso pós-Washington", principalmente no tocante à revisão da forma do Estado mínimo, quer seja de rever os modos de privatização em linha direta e se constituir novas funções para os Estados na contemporaneidade econômico-produtiva. Decorrente disso, o setor privado imbui-se de "assumir a forma de comercialização, tais como ter direitos exclusivos para vender refrigerantes, ou fornecer materiais curriculares" (ROBERTSON; VERGER, 2012, p. 1137).

Neste contexto, os desígnios do Consenso de Washington foram reabilitados e expandidos "para incluir uma série de reformas adicionais com a rubrica da "boa governança": extensivas reformas na administração pública, PPPs, a eliminação de barreiras comerciais e uma nova leva de acordos no mercado internacional" (ROBERTSON, 2012, p.287).

Para Di Pietro (2014), PPPs é o termo utilizado para designar todas as formas de sociedade que, sem formar uma nova pessoa jurídica, são organizadas entre os setores públicos e privados no atendimento ao interesse público. No campo da educação, são perceptíveis os avanços dos arranjos entre instituições privadas e setores públicos na prestação de vários serviços, dentre eles: formação de gestores 
e professores, consultoria em gestão de redes e escolas, materiais pedagógicos, currículos, apostilamentos, entre outros.

Concorda-se com Pires (2015) quando argumenta que, historicamente, a educação pública brasileira foi expressão dos interesses da esfera privada. Em análise realizada desde o final do século XIX até os dias atuais, a autora percorre os diferentes períodos da república nacional e seus dispositivos legais para chegar à conclusão que, embora recentemente o Estado tenha se aproximado da titularidade na promoção da educação, admitindo a sua função, as forças sociais privatizantes se organizaram para deslegitimar essas pretensões, reafirmando o caráter privatista da educação pública.

Para Robertson e Verger (2012), as PPPEs são, sobretudo, "relações sociais e econômicas (WEIHE, 2010), envolvem questões de poder, autoridade, legitimidade, responsabilidade e igualdade, e não apenas mecanismos de opção com base no mercado e em ganhos de eficiência" (JAYASURIYA, 2008, p.1150).

Essas transformações têm implicações importantes para o contrato social entre educação e Estado e, em particular, para a educação como bem social complexo.

\section{Governança em rede e políticas educacionais}

Na lógica da NGP/gerencialismo, a noção de governança passa a ser amplamente difundida como parte da nova ordem mundial e mecanismo de modernização do Estado, em que este, enxuto, assume as funções que lhe são exclusivas, repassando à sociedade civil e às suas organizações a responsabilidade na execução em alguns casos e, em outros casos, compartilhando responsabilidades, seja no planejamento, no provimento ou na execução de políticas.

O termo governança é originado do inglês governance, cuja formalização ocorre na área econômica. Para Reis (2013, p.107), pode ser entendida como "o modo de coordenação dos diferentes tipos de arranjos institucionais presentes num dado sistema social de produção - mercados, hierarquias, Estado, redes, associações e comunidades, cujas ordens relacionais, diversas e parciais, configuram uma dada forma institucional".

A governança evidencia um conceito mais aberto e distintivo, que na esfera pública remete aos padrões de articulação e de cooperação das ações, dos processos, dos mecanismos e das estratégias de um governo, o qual incita transformações nas formas de governo e controle do Estado "tido como monolítico, para uma perspectiva pluricêntrica, de governança descentralizada, realizada por redes de múltiplos 'atores'" (SHIROMA; EVANGELISTA, 2014, p. 24).

Reis (2013) identifica diversas abordagens sobre governança, mas destaca duas delas: boa governança (good governance) e governança empresarial/corporativa (corporate governance), como bases do projeto de governança pública dos Organismos Multilaterais 
(OM). Em 1991, o Banco Mundial (BM), uma das agências centrais na promoção do Consenso de Washington, publicou o Relatório sobre o Desenvolvimento Mundial (RDM), com o intuito de compilar suas perspectivas. No ano seguinte, em 1992, adensou seus propósitos com apoio do documento Governance and Development (WB, 1992), chamando para si o papel de liderar o processo de reforma do Estado priorizando quatro áreas: "accountability, enquadramento legal para o desenvolvimento, informação e transparência" (p. 2, tradução autoral ${ }^{3}$ ). Para tanto, tais reformas deveriam ser conduzidas por meio da ideia de boa governança (good governance) como categoria chave, sendo "a boa governança, para o WB, sinônimo de boa gestão do desenvolvimento" (WB, 1992, p.1, tradução autoral ${ }^{4}$ ).

A noção de governança empresarial deriva do conjunto de princípios básicos para aumentar o controle do mercado sobre as organizações, listados por Osborne e Gaebler (1994) e que sustentaram a Organização para a Cooperação e Desenvolvimento Econômico (OCDE) a partir dos anos 1990 (SECCHI, 2009). Em 1999, a organização apresentou um conjunto de princípios de governança corporativa, o qual atualizou em 2004 e novamente em 2015, focalizando três eixos: eficácia, transparêcia e accountability (OECD, 2015). Dessa maneira, é um conceito que dá suporte às alterações do papel do Estado em escala global, exprimindo procedimentos e práticas governamentais relevantes ao processo decisório. As PPPs emergem visando à participação de diferentes setores na formulação e na execução de políticas e em distintas esferas de poder. Nesta perspectiva, a governança alude mudanças:

[...] operadas nas sociedades com o advento da globalização neoliberal provocaram alterações no papel e funções dos Estados nacionais, bem como nas relações dos países entre si. Surgiram novos atores supranacionais, mediadores das relações econômicas, ambientais, sociais, e em outras áreas antes consideradas estratégias e de responsabilidade de cada nação, como é o caso da educação. $\mathrm{A}$ essa nova configuração, os seus formuladores, notadamente os organismos internacionais, deram o nome de "governança". A ideia é de alargamento das relações e de ampliação das possibilidades de atingir objetivos e metas em favor do "bem comum", contando com a participação e colaboração de parceiros, quer sejam países, instituições, pessoas, para além do Estado, visto que este, sozinho, na acepção dos formuladores, não consegue dar conta (CÓSSIO, 2015, p. 623).

A reforma do Estado brasileiro, iniciada na década de 1990, como já citamos, deu sustentação jurídica à criação de instituições da sociedade civil, consideradas de interesse público (OS e OSCIP) e incentivou a criação de legislações estaduais. No caso do RS, por exemplo, foi sancionada a Lei $n^{\circ} 12.234$, de 2005, que legalizou a licitação e a contratação de $\operatorname{PPPs}(R S, 2005)$. No entanto, as primeiras iniciativas de PPPs em nível estadual se materializaram de fato após a aprovação da Lei 12.901 de 2008, que regulamentou as OCIPS, propiciando a efetivação de convênios. No caso da educação, foi criado o Programa "Boa Escola para Todos", que segundo Amaral (2010) identificou, realizou diversos convênios entre órgãos públicos (CONSED; SINEPE/RS; ACPM/RS; AESUFOPE; UNDIME/RS; UNESCO) e grupos privados (Unibanco; Gerdau; Aracruz/Copesul; Marcopolo; IAS; ALFA e BETO; GEEMPA).

Em uma fase mais atual, o governador Sartori (Governo 2015-2018) modificou a Lei $n^{\circ} 12.234$ de 2005 via Lei $n^{\circ} 14.686$ (RS, 2015), que institui o Programa de Parcerias Público-Privadas do Estado do RS - PPP/RS, e inclui a Manifestação de Interesse da Iniciativa Privada para atuar na esfera pública estadual. 
A partir do ordenamento jurídico nacional e local, os grupos privados passam a atuar, entre outras formas, por meio de OSs e OSCIPs, tanto se apresentando como novos atores em um quadro de ineficiência do Estado, como incentivando modos de governo flexível, descentralizado e pró-mercado, constituindo o rizomático arranjo institucional que caracteriza a governança.

Observamos desde o final da década de 1990 que, com base no projeto da Terceira Via que deu destaque ao terceiro setor, com o advento da NGP/gerencialismo e por meio da lógica de governança voltada à reforma do Estado, as PPPs têm encontrado cada vez mais espaço para influenciar na forma de organização e nas funções do Estado em diferentes regiões e locais. No caso das PPPEs, a lógica privada se introduz no setor educacional, incidindo significativamente na condução e na efetivação das políticas públicas. Segundo Peroni (2013b, p.7), "a parceria entre instituições do terceiro setor e sistemas públicos de educação é uma das principais formas de relação entre o público e o privado atualmente no Brasil". Para Shiroma (2016), a governança constitui redes que reúnem Organismos Multilaterais (OM), governos nacionais, ONGs, think thanks, grupos de interesse, consultores, empreendedores sociais e corporações transnacionais que se aninham em teias de relações, ampliando sua possibilidade de impacto e influência, conferindo autoridade e legitimidade às questões globais, sobretudo, na esfera educativa.

Em seus estudos, Ball (2014) tem usado a concepção de redes como conceito teórico para analisar as políticas educacionais no âmbito da lógica de governança em rede, no quadro do programa neoliberal, entendendo-a como um meio de criação de novas oportunidades de lucro por meio de relações e interações de forma que "ideias, discursos, dinheiro e pessoas se movem por meio delas" (BALL, 2014, p.19). Neste sentido, as redes políticas expressam um tipo de "social" novo, envolvendo relações sociais em fluxos e movimentos, que permitem espaço para novas vozes dentro do discurso de políticas que promovem novas narrativas para orientar as políticas.

Esta discussão é central para sustentar o estudo das PPPEs e das redes políticas, o qual, conforme apresentamos na próxima seção, vem sendo pesquisado por meio do mapeamento dos entes privados mais recorrentes na educação no Estado do RS e, a partir disso, pela análise das redes de políticas que são estabelecidas, bem como seus propósitos e efeitos na educação pública.

\section{As Parcerias Público-Privadas em Educação - PPPEs no Estado do RS}

O conceito de redes também é usado por Ball (2014) como um método analítico para contemplar a estrutura das comunidades políticas e alguns aspectos visíveis nas relações sociais estabelecidas, por meio do que ele chama de "etnografia de rede". É uma metodologia que permite realizar o mapeamento da forma e do conteúdo das relações 
políticas em um campo particular, uma variação que Bervir e Rhodes (2006) apresentam como "análises etnográficas de governança em ação" (BALL, 2014, p. 28). Propõe expandir as perspectivas de análise com apoio de novas fontes de dados, emanadas pela comunicação virtual e eletrônica, de forma a permitir o acesso mais amplo e mais rico das relações sociais em redes, do que possibilitam os dados terrestres.

$\mathrm{Na}$ pesquisa em realização, adotamos o método de etnografia de rede, tendo como lócus de investigação as escolas públicas municipais e estaduais. Para realizar o levantamento das PPPs, usamos como base a organização da Secretaria de Educação (SECUD/RS), que agrupa as 497 cidades do RS em 36 Coordenadorias Regionais de Educação (CREs). No levantamento das PPPEs, utilizamos diferentes combinações de descritores, tais como: programa, projeto, formação, convênio, adicionados ao nome de cada município. Como instrumentos de pesquisa, contemplamos os sites de entidades representativas dos Secretários de Educação (Municipais e Estadual), dos Conselhos de Educação, das Secretarias de Educação, dos materiais de divulgação e das empresas consultoras, dos vídeos promocionais, das páginas do Facebook, dos blogs, das entrevistas e das falas em eventos.

O levantamento revelou que os atores privados que atuam de forma mais recorrente como parceiros das redes públicas são: Instituto Natura, Instituto Ayrton Senna (IAS), Federação Nacional das Associações do Banco do Brasil (FENABB), Sistema de Crédito Cooperativo (SICREDI) e Associação dos Fumicultores do Brasil (AFUBRA). Destes cinco, apenas a FENABB não foi verificada como sendo uma OSCIP. O Instituto Natura e o IAS foram os predominantes, sendo que o Instituto Natura foi encontrado em 12 CREs e 62 cidades e o IAS em 20 cidades e 12 CREs, conforme demonstramos no Quadro 1.

Quadro 1 - Instituições privadas, com ou sem fins lucrativos, que atuam em parceria com os sistemas públicos no Estado do RS.

\begin{tabular}{|l|l|l|}
\hline & $\begin{array}{l}\text { Frequência (nº de } \\
\text { CRES) }\end{array}$ & $\begin{array}{l}\text { Presença em ci- } \\
\text { dades }\end{array}$ \\
\hline Instituto Natura & 12 & 62 \\
\hline Instituto Ayrton Senna (IAS) & 12 & 20 \\
\hline $\begin{array}{l}\text { Federação Nacional das Associações Atléticas } \\
\text { do Banco do Brasil (FENABB) }\end{array}$ & 10 & 18 \\
\hline Sistema de Crédito Cooperativo (SICREDI) & 08 & 18 \\
\hline $\begin{array}{l}\text { Associação dos Fumicultores do Brasil (AFU- } \\
\text { BRA) }\end{array}$ & 07 & 18 \\
\hline
\end{tabular}

Fonte: NEPPE (2017).

Quanto ao Instituto Natura, constatamos que a sua criação como OSCIP ocorreu em 2010, visando ao fortalecimento e à ampliação da sua atuação na esfera da educação. Realiza diversos projetos, tais como: Escola em Tempo Integral, Rede de Apoio à Educação, 
Escola Digital, Comunidade de Aprendizagem e o Trilhas, além de apoiar várias iniciativas da sociedade civil. Tem como parceiros em seus projetos a Fundação Lemann, Fundação Itaú Social, Fundação Telefônica Vivo, Instituto Ayrton Senna - IAS, Fundação Roberto Marinho, Fundação Victor Civita, entre outros, dando mostras de articulação em rede (INSTITUTO NATURA, 2017). Sua inserção nas escolas do RS foi identificada por meio da plataforma digital "Trilhas", que é voltada a apoiar professores que atuam nos anos iniciais do Ensino Fundamental, até o $2^{\circ}$ ano, no processo de alfabetização, por meio de formação continuada a distância. O IAS foi localizado a partir de cinco diferentes projetos e ações educacionais: os Projetos de alfabetização: Se Liga, Acelera e Gestão da política de alfabetização; Gestores em rede, e o mais recente projeto, Letramento em Programação Digital. O instituto atua desde 1994, quando foi criado como uma organização não governamental sem fins lucrativos, visando à melhoria de sistemas públicos educacionais por meio de soluções replicáveis em larga escala voltadas à educação integral e à alfabetização de crianças e jovens, tendo obtido a certificação de OSCIP em 2004, o que permitiu firmar parcerias com o setor público (IAS, 2017).

Depreendemos que o IAS e o Instituto Natura são duas entidades privadas, sem fins lucrativos, que se destacam como parceiros privilegiados das redes públicas de educação. Nos sites institucionais do IAS e do Instituto Natura, evidenciamos os diferentes espaços políticos nos quais participam, como no movimento "Todos pela Educação" (TPE, 2018), em que se inserem diversas organizações privadas e que desde 2014 se tornou uma OSCIP; e, mais recentemente, o Movimento pela Base (MPB, 2018), que tem como principal objetivo a aprovação e a materialização da Base Nacional Curricular Comum (BNCC) para a educação básica nas escolas brasileiras. Pela amplitude de parceiros, de programas e de atuação no Estado do RS, analisaremos estes dois parceiros mais detidamente na segunda etapa da pesquisa.

O principal programa da FENABB é o "AABB Comunidade". O programa tem o objetivo de promover o desenvolvimento integral dos estudantes de escolas públicas, a fim de promover complementação educacional dentro das Associações Atléticas Banco do Brasil (AABB), além da oferta de atividades lúdicas em áreas de saúde e higiene, esporte e linguagens artísticas, como meio de inserção social a crianças e adolescentes de famílias de baixa renda entre 06 e 18 anos (AABB COMUNIDADE, 2017). Encontramos este programa educativo da FENABB presente em 10 CREs e 18 cidades do Estado e a partir da exploração de análise do programa, pudemos compreender um pouco da ampla rede que a federação mantém e que tornou tal programa um dos carros chefes da federação.

Ao analisarmos o projeto pedagógico do AABB Comunidade da FENABB, é preciso destacarmos que, embora o programa sinalize para alguns princípios relacionados aos direitos humanos, à democracia e à Pedagogia libertadora, referencia em muitos momentos a perspectiva do Banco (Banco do Brasil) o qual se atrela, e que se configura como economia mista, com personalidade jurídica de direito privado. Documentos de base do Programa AABB Comunidade apresentam aproximações com a lógica gerencial, 
tais como o direcionamento de didáticas (manuais de planejamento) e a realização de modos de controle (via Monitoramento e Avaliação In loco), assim como a perspectiva pedagógica que valoriza o empreendedorismo e o voluntariado. Assinala para o resgate das pessoas da condição de miséria, ofertando atividades complementares, mas pouco aprofunda o debate quanto à transformação social da população que atende.

No que se refere às articulações da FENABB, é possível evidenciar uma série de relações que mantém para o provimento de suas ações. Elas são organizadas em três diferentes grupos: parceiros, conveniados e entidades vinculadas (FENABB, 2017). Sobre os últimos, depreendemos que são, basicamente, oito instituições do grupo BB, o que certamente evidencia a proeminência deste ente em se manter com relações mais fugazes com outros entes, e sustentar-se no estabelecimento de relações fixas e que atendem aos seus interesses com seus próprios membros.

O Estado do RS se destacou pela amplitude de conveniamentos da FENABB, sendo a unidade do país com mais convenentes listados, desde relações com Secretarias de Educação (estadual e municipais) e, principalmente, sindicatos e associações de empresas estatais, como Sindicato dos Correios e Telégrafos; Três Potências Maçônicas do RS, Associação dos Servidores da Previdência e Seguridade Social do RS, etc. Destaca-se também como o terceiro maior estado em número de AABBs ativas, com131 unidades em funcionamento. É o segundo ente nacional que mais oferta o Programa AABB Comunidade, estando somente atrás de Minas Gerais.

Outro fato importante é que identificamos outras instituições, que não as Prefeituras Municipais, as quais são referidas como as grandes promotoras locais no provimento do programa. Esse cenário foi encontrado em cinco municípios e foram localizadas as seguintes instituições: Universidade Regional Integrada do Alto Uruguai e das Missões (URI) em Frederico Westphalen; Universidade do Vale do Rio dos Sinos (UNISINOS) em São Leopoldo; em Ijuí, com a Fundação de Integração, Desenvolvimento e Educação do Noroeste do Estado (FIDENE) - constituída pela Universidade Regional do Noroeste do Estado do Rio Grande do Sul (UNIJUÍ), pelo Centro de Educação Básica São Francisco de Assis (EFA) e pelo Museu Antropológico Diretor Pestana (MADP) e pela Rádio e Televisão Educativa (RTVE); a parceria com a Assistência Social Lagoense em Lagoa Vermelha; e, a mais destacada, o convênio com o Instituto Cooperforte em Porto Alegre.

Ao explorar a rede de relações da FENABB, principalmente contornando o Programa AABB Comunidade, alguns parceiros se salientaram, considerando que reconhecemos como parceiro todo e qualquer ente com relações com a federação, sobretudo no que tange ao programa educativo em foco. Assim, na dimensão financeira, identificamos a importância da Federação do Banco Brasil (FBB) como promotora do programa com a FENABB; a Cooperativa de Economia e Crédito Mútuo dos Funcionários das Instituições Financeiras Públicas Federais Ltda (Cooperforte) e o Bancorbrás como parceiros recorrentes em atividades do programa; além do Banco Votorantim, um ente que não 
é parte do grupo Banco do Brasil (BB). Outros parceiros mapeados foram o Núcleo de Trabalho Comunitário (NTC) da Pontifícia Universidade Católica de São Paulo (PUC/SP) e o CESAR, com quem são mantidas, respectivamente, relações mais fixas e em projeto piloto da federação, respectivamente; sem contar as relações com o BB e suas agências em diferentes espaços e momentos. Além disso, no âmbito de aparentes conveniados, para trocas de serviços, detivemos a análise em três entidades: Grêmio TAM, GreenVision, Caixa de Assistência dos Funcionários do Banco do Brasil (CASSI) e MAPFRE Seguros.

Em relação ao SICREDI, evidenciamos que está inserido em escolas de 08 CREs e 18 municípios do RS a partir dos programas "A União faz a vida" e "Educação Financeira" em parceria com o Banco Central. SICREDI é a marca assumida desde 1992 pelo primeiro Banco cooperativo privado do Brasil, que nascido no Estado do RS, atualmente tem abrangência nacional. Sua fundação como OSCIP aconteceu em 2010 e passou daí em diante a estabelecer termos de parcerias com o setor público. No seu histórico são destacadas as parcerias, em 2010 com o Rabo Financial Institutions Development, braço de desenvolvimento do grupo holandês RABOBANK, sistema de crédito cooperativo presente em 40 países; e no ano seguinte, em 2011, o conveniamento com a International Finance Corporation (IFC), organização parte do Grupo Banco Mundial, que investe no setor privado nos países em desenvolvimento.

O Programa União Faz a Vida é a principal iniciativa de responsabilidade social na esfera educativa do SICREDI. Segundo as informações coletadas, o objetivo deste programa é construir e propiciar vivências de atitudes e valores de cooperação e cidadania, por meio de práticas de educação cooperativa, contribuindo para a educação integral de crianças e adolescentes em âmbito nacional. Desta forma, o público são alunos do Ensino Fundamental do $3^{\circ}$ ano ao $5^{\circ}$ ano, e jovens alunos do $6^{\circ}$ ano do Ensino Fundamental ao Ensino Médio. O programa foi iniciado em 1995 para ampliar o conhecimento das comunidades sobre o cooperativismo e a natureza das sociedades cooperativas. Sua proposta foi construída a partir de exemplos internacionais e da parceria com o Centro de Desenvolvimento e Pesquisa sobre Cooperativismo da Universidade do Vale do Rio dos Sinos (UNISINOS, São Leopoldo/RS). Os projetos cooperativos são desenvolvidos pelos alunos nas escolas, com o apoio de educadores, pais e da comunidade.

Conforme o relatório do Programa União Faz a Vida, sua presença acontece em sete estados do país (RS, SC, PR, SP, GO, MT e MS), tendo atingido em 2017: 292 municípios, 1.485 escolas, 21.940 educadores e 229.780 alunos. Somente no Estado do RS foram identificados, por meio das 26 cooperativas estaduais: 138 municípios, 750 escolas, 9.512 educadores, 93.320 crianças e adolescentes. É importante destacar que a participação no programa ocorre pelo convênio das prefeituras, via secretarias de educação, com a unidade do SICREDI municipal.

No site oficial do programa (SICREDI, 2017) e no Facebook é compartilhada grande parte das iniciativas escolares, ilustrando a disseminação de ideias e propostas nas 
diferentes fases da Educação Infantil às séries iniciais e finais do Ensino Fundamental. De acordo com o SICREDI, para a promoção do programa, é fundamental a participação de vários agentes que compõem o que chamam de rede de cooperação. Cada um dos agentes tem igual importância, mas há responsabilidades distintas entre os grupos, que são divididos em Gestores (entidades integrantes do SICREDI); Apoiadores (comunidade); Parceiros (Secretarias de Educação e Instituições educacionais) e Assessoria Pedagógica (Universidades ou outras instituições especializadas).

Para os fins desta pesquisa, entendemos que as instituições que prestam a assessoria pedagógica são parceiras essenciais para o SICREDI desenvolver seu programa educativo. Segundo as informações disponibilizadas no site do Programa União Faz a Vida, as assessorias são contratadas pelo Gestor, tendo o papel de promover a formação continuada dos educadores que conduzirão o processo de formação das crianças e dos adolescentes. As assessorias pedagógicas são formadas por profissionais de instituições de ensino superior, institutos, centros de pesquisa, entre outros, que atendam aos requisitos técnicos exigidos para promover a formação dos educadores.

Para identificar os principais parceiros no trabalho de assessoria pedagógica, foi analisada a incidência (do maior ao menor grau) de cada assessoria no Estado do RS, a partir do que se elencaram cinco instituições, que somam juntas mais de $50 \%$ das consultorias realizadas com o programa no Estado. São elas: Instituto de Educação Superior de Ivoti (ISEI), Instituto de Desenvolvimento Educacional do Alto Uruguai (IDEAU), Universidade de Santa Cruz (UNISC), Universidade Luterana do Brasil (ULBRA) e Universidade Regional Integrada do Alto Uruguai e das Missões (URI). Destacamos que todas são entidades privadas, ainda que, em sua maioria, não estejam classificadas como particulares, com fins lucrativos.

Ressaltamos que o programa apresenta como um dos principais objetivos a disseminação da educação financeira e cooperativa, articulada às ideias de empreendedorismo, aprendizagem ao longo da vida e de flexibilidade. Tais elementos ilustram se associar, em grande medida, aos eixos promovidos pelo metabolismo econômico do projeto global, cuja organização se filia como um banco que sofreu transformações, passando de um sistema cooperativo de crédito que sustentou a iniciativa de trabalhadores de fábricas, para uma instituição financeira em sentido estrito.

A AFUBRA se insere na educação a partir do Programa "Verde é Vida", desenvolvido nos estados do sul do país (RS, SC e PR), o qual apareceu presente em escolas de 07 CREs e 18 cidades no Estado do RS. A instituição se volta à distribuição de mudas nativas, sendo que o Programa "Verde é Vida" direciona-se, especificamente, à educação socioambiental, por meio da preservação do ambiente, educação no meio rural, sustentabilidade, diversificação e valorização dos agricultores.

A AFUBRA tem como foco o trabalho na cadeia produtiva de fumígenos, operando de forma associativa desde sua constituição em 1955 no RS. A organização tem origem na 
cidade de Santa Cruz, expressiva região de fumo no país, e onde encontramos unidades de grandes empresas fumageiras nacionais e internacionais (Souza Cruz; CTA; Universal etc). Em 1960, a AFUBRA criou o departamento de fomento agropecuário com o objetivo de oferecer orientação técnica gratuita, além de sementes, insumos e implementos agrícolas aos produtores de tabaco (AFUBRA, 2017). Em 1963 passou a atuar também nos estados de SC e PR, e em 1994 ampliou sua atuação pela criação da Agrocomercial AFUBRA Ltda, quando a associação aumentou sua linha de produtos e serviços, que atualmente está presente com 22 unidades nos três estados onde atua, oferecendo, além de linhas agrícolas, artigos gerais (móveis, eletrodomésticos, artigos para casa, etc.) e planos de consórcio.

Na sua página oficial, a AFUBRA apresenta parcerias com diversas entidades do ramo fumageiro, como: International Tabacco Growers Association (ITGA); Instituto Brasileiro do Meio Ambiente e dos Recursos Naturais Renováveis (IBAMA); bem como conselhos regionais, municipais e outros grupos que desenvolvem ações específicas à questão fumageira. Na esfera ambiental e educacional, desenvolve o Programa "Bolsa de Sementes", uma parceria com a Universidade Federal de Santa Maria (UFSM), o qual, pelas análises que realizamos, reconhecemos como sendo o parceiro mais efetivo da organização no âmbito do Programa Educativo Verde é Vida. A AFUBRA atua ainda na promoção do Projeto "O Futuro é Agora", atualmente chamado de Instituto Crescer Legal, coordenado pelo Sindicato Interestadual da Indústria do Tabaco (SINDITABACO) e empresas associadas do ramo fumageiro, com o intuito de apoiar jovens no que se refere à produção do fumo de forma a incentivá-los a essa atividade.

É importante destacar que a AFUBRA se constitui como uma entidade de classe, sem fins lucrativos (AFUBRA, 2017). Logo, é um tipo de entidade que não sofre encargos tributários de impostos, atuando na prestação de serviços, como a educação, colocando à disposição da população em geral, com um caráter complementar, as atividades do Estado. De forma específica, a AFUBRA tem como um dos principais objetivos a gestão de um seguro mútuo para a lavoura dos produtores contra os prejuízos causados pelas chuvas de granizo que ocorrem frequentemente (TELÓ, 2016). Representa, assim, juntamente com o Sindicato dos Trabalhadores Rurais, os interesses dos produtores de fumo (ZANELLA; PRIEB, 2007). De forma ampla, a associação divulga em sua página oficial que sua missão é:

Proporcionar o bem-estar aos associados, clientes e comunidades, através do mutualismo, de programas socioambientais, de soluções no comércio de bens e serviços e de alternativas na agricultura familiar e no agronegócio. (AFUBRA, 2017).

Destacamos o fato de a AFUBRA buscar, por meio das ações educativas e sociais de cunho ambiental, eclipsar os malefícios causados pelo fumo. Assim, com relação ao âmbito escolar, a AFUBRA realiza ações de sensibilização das comunidades pela distribuição de mudas nativas. No ano de 1981, a AFUBRA e o então SINDIFUMO atual SINDITABACO - assinaram um convênio com o IBAMA, o qual visava incentivar o reflorestamento das propriedades rurais (AFUBRA, 2011). Ao crer nos efeitos positivos dos trabalhos ambientais desenvolvidos na sociedade, foi oficialmente criado, em 1991, 
o Programa Verde é Vida. O programa se volta aos produtores, aos comerciantes e aos consumidores de fumo, no sentido de conscientizar sobre os cuidados necessários com a natureza e com a produção do fumo, o que permite a manutenção de circulação da cadeia produtiva e dos negócios da entidade.

Após a identificação dos principais programas e projetos realizados por estas cinco instituições em parceria com as redes públicas, processamos a localização de parceiros privados que atuam em colaboração permanente ou eventual com cada um deles. O objetivo deste momento é o de visualizar as redes políticas, os parceiros mais recorrentes e os níveis de intensidade em que atuam. Ao realizarmos este mapeamento, observamos o IAS como o ente com maior número de parceiros e maior inserção nas redes escolares, seguido do Instituto Natura. A FENABB e o SICREDI que, à primeira vista se apresentavam como entes mais localizados e individuais, mostraram-se com várias articulações. Afora isso, identificamos também a articulação entre o IAS e a FENABB, mas é preciso verificarmos outras ramificações para esquematização das redes.

Para adensamento da análise das redes, após localizarmos os principais parceiros de cada ente situado na primeira etapa da pesquisa, adaptamos as propriedades de rede, sugeridas por Tichy e colaboradores (1979, p. 508), e citadas por Lopes e Baldi (2009), buscando contemplar a diversidade de esferas dessas relações e a natureza das ligações, observando questões de conteúdo, intensidade, reciprocidade, clareza, multiplexidade; e características estruturais, como tamanho, densidade, clustering e centralidade. Com apoio desses elementos, cada ente está sendo analisado em relação aos itens destacados, para posteriormente serem cotejados entre si, procurando verificar se possuem parceiros em comum, objetivos e intencionalidades que se aproximam e em que e como se diferem e distanciam. De posse dessas informações, pretendemos esquematizar as redes com o uso do Programa Gephi 9.0, que possibilita este fim.

\section{Considerações finais}

Esta pesquisa, como já referimos, tem como objetivo identificar as instituições privadas, com ou sem fins lucrativos, mais recorrentes nas escolas e nos sistemas de ensino públicos do Estado do RS por meio de PPPEs. Por meio do levantamento nas 36 Coordenadorias de Educação presentes nos 497 municípios estaduais, identificamos cinco entes prevalecentes e que, em ordem de maior recorrência, foram: Instituto Natura, IAS, FENABB, SICREDI e AFUBRA. Os dois primeiros, que foram os mais presentes em conveniamentos, foram identificados como dois expressivos grupos de atuação em redes de ensino públicas e em movimentos políticos do país, como o TPE, o MPB e a BNCC, o que levou a pesquisa a centrar-se no aprofundamento dos três últimos entes, que se apresentavam, pelo menos em primeira vista, como menos expressivos e com atuação mais regionalizada, reservando os dois primeiros para a segunda etapa da pesquisa. 
Ao aprofundarmos as análises, observamos vastas articulações da FENABB e do SICREDI, mesmo que com entidades do próprio grupo, como no caso da FENABB e as empresas do BB, ou com instituições educacionais, como no caso do SICREDI. O fato é que identificamos relações mantidas pelos entes em busca de legitimação, organicidades de seus propósitos e fortalecimento de suas ideias e propostas. A AFUBRA, ainda que menos expressiva em relações, mantém vínculos da área em que atua, que, em verdade, parece ser seu objetivo, que é do fortalecimento da cadeia econômica e produtiva fumageira, bem como a relação comunitária que é uma de suas bases, funcionando como fator chave para expandir seus negócios.

Assim, no que tange às questões educativas de cada ente, foi possível verificarmos as propostas e as relações em rede mantidas pela FENABB, AFUBRA e SICREDI, voltando a atender determinados interesses e motivações específicas. Os discursos sociais e assistencialistas são presentes em cada um, mesmo que com peculiaridades em vista do enfoque ao qual se vinculam, da questão ambiental, fumageira, cooperativa ou ainda sócio-comunitária. Observamos, em grande medida, ideias gerenciais e de incursão de elementos mercantis em todas as propostas, por meio do enfoque cooperativo, empreendedor, apontando uma tentativa de diminuir as consequências do mercado sobre a sociedade e manter as relações de consumo e produtividade.

No processo de análise das redes que cada instituição mantém, ressaltamos logo de antemão as relações dos programas educativos do IAS e da FENABB, evidenciando uma ramificação entre os dois entes. Ressaltamos também as articulações de todos os entes com Instituições de Ensino Superior (IES): FENABB com a PUC/SP; SICREDI com diversas IES na prestação de assessoramento pedagógico; AFUBRA com a UFSM, destacando-se a AFUBRA como a única com parcerias com uma universidade pública.

Ainda em relação à participação das IES, evidenciamos duas parceiras presentes em mais de um ente: a UNISINOS, que é parceira local da FENABB na oferta do AABB Comunidade em São Leopoldo e que mediou a criação da proposta do Programa União Faz a Vida, por meio do Centro de Desenvolvimento e Pesquisa sobre Cooperativismo vinculado a esta universidade; e a URI, que é apresentada como promotora local do AABB Comunidade da FENABB na cidade de Frederico Westphalen e uma das cinco mais expressivas entidades que prestam assessoria pedagógica ao Programa União Faz a Vida do SICREDI.

Ao cotejar as PPPEs presentes na educação do Estado do RS e as redes que mantêm, reconhecemos que expressam novas relações entre Estado, mercado e sociedade civil em avanço dentro de uma perspectiva da governança, que impulsiona a constituição de redes de transferência e influências políticas (CÓSSIO, 2015). Esses conceitos elucidam novas formas políticas no setor público, as quais têm repercussões nas políticas educacionais e seus desdobramentos quanto à organização, à gestão, à avaliação e à concretização dos processos escolares. 
Nas entidades destacadas com atuação na educação, evidenciamos em todas a intenção de promover uma lógica societária em articulação à ideia empresarial, direta ou indiretamente, seja pelo conteúdo do próprio programa, como é o caso do SICREDI, por meio da educação financeira; seja pela ênfase na lógica do reforço escolar e em conteúdos mínimos entendidos como necessários ao processo produtivo, como no caso da FENABB, ou na especificidade da AFUBRA, que busca compensar os males provocados pelo fumo por meio de atividades de educação ambiental. Nos casos do IAS e do Instituto Natura, são visíveis suas motivações empresariais, quando participam ativamente em muitas redes políticas que manifestam os ideais mercantis e defendem a incursão de tais propósitos na educação pública, embora o segundo (Instituto Natura) tenha um viés bem menos incisivo sobre essas questões quando relacionado ao primeiro (IAS).

Os encaminhamentos desta pesquisa até aqui levam a considerar que a discussão sobre as redes de políticas é importante no que tange à definição da educação, pois,

Com os novos sujeitos que passam influenciar fortemente as políticas educacionais como instituições filantrópicas e redes globais, as responsabilidades ficam cada vez mais diluídas quanto à responsabilidade pela execução do direito à educação. Enfatizamos que entendemos redes como sujeitos (individuais ou coletivos) em relação, situados em um contexto histórico e geográfico (HARVEY, 2005) e perpassados por objetivos de classe. As formas de redes em si podem ser instrumentos para mais participação ou, ao contrário, para controle e jogo de influência. Neste sentido, a questão central é que a rede, em nosso entendimento, não deve substituir o poder público na execução dos direitos sociais e no debate público acerca do conteúdo da educação, através da concepção de pedagogia, currículo e avaliação vinculada ao debate acerca do papel do conhecimento em um projeto societário mais justo e democrático (PERONI, 2015, p. 15-16).

Assim, é preciso questionar a falta de representatividade social, de compromissos com justiça social e com a materialização de direitos quando os grupos e/ou redes substituem o poder público e reconfiguram os princípios e os propósitos da educação na perspectiva mercantil. Peroni (2015) alerta que esses grupos não sãos uma abstração, sendo formados e operados por sujeitos em um projeto de classe.

Compreendemos que as PPPEs potencializam, em escala abrupta, um avanço em nível global do setor privado, o qual passa a estar, então, "profundamente enraizado no coração dos serviços públicos educacionais" (ROBERTSON, 2012, p.1149). Diante de tal prerrogativa, consideramos que as PPPEs se encaixam em um projeto mais amplo de reconstituição da educação pública no âmbito de uma sociedade pró-mercado.

\section{Referências}

AFUBRA, Associação dos Fumicultores Do Brasil. Cadeia produtiva do tabaco assina termo de compromisso com IBAMA. Publicado em 23, agosto de 2011. Disponível em: <https:// afubra.com.br/noticias/479/cadeia-produtiva-do-tabaco-assina-termo-de-compromissocom-ibama.html >. Acesso em: 29/05/2018.

. Site institucional. Disponível em: <https://afubra.com.br>. Acesso em 30/10/2017. 
AMARAL, J. R. A política de gestão da educação básica na rede estadual de ensino do Rio Grande do Sul (2007-2010): o fortalecimento da gestão gerencial. 2010. Programa de PósGraduação em Educação (Tese). Porto Alegre: UFRGS, 2010.

BALL, S. J. Educação global S.A: Novas redes políticas e o imaginário neoliberal. Ponta Grossa: UEPG, 2014.

BRASIL. Emenda constitucional n 19, de 1998: Modifica o regime e dispõe sobre princípio e noras da administração pública, servidores e agentes políticos, controle de despesas e finanças públicas e custeio de atividades a cargo do distrito federal, e dá outras providências. Brasília, 1998.

Lei $\mathbf{n}^{\circ}$ 9.637, de 15 de maio de 1998. Dispõe sobre a qualificação de entidades como organizações sociais, a criação do programa nacional de publicização, a extinção dos órgãos e entidades que menciona e a absorção de suas atividades por organizações sociais, e dá outras providências. Brasília, 1998.

Lei $\mathbf{n}^{\circ} \mathbf{9 . 7 9 0}$ de 23 de março de 1999. Dispõe sobre a qualificação de pessoas jurídicas de direito privado, sem fins lucrativos, como Organizações da Sociedade Civil de Interesse Público, institui e disciplina o Termo de Parceria, e dá outras providências. Brasília, 1999.

Lei no 11.079, de 30 de Dezembro de 2004. Institui normas gerais para licitação e contratação de parceria público-privada no âmbito da administração pública. Brasília, 2004.

. Lei 13.204 de 14 de dezembro de 2015. Altera a Lei no 13.019, de 31 de julho de 2014. Brasília, 2015.

BRESSER PEREIRA, L. C. A Reforma do estado dos anos 90: lógica e mecanismos de controle. Brasília: MARE, 1997.

CÓSSIO, M. de F. Agenda transnacional e governança nacional: as possíveis implicações na formação e no trabalho docente. Revista e-Curriculum, São Paulo, v.13, n.04, out/dez, 2015, p. 616-640.

DI PIETRO, M. S Z. Direito administrativo. São Paulo: Atlas, 2014.

FENABB, Federação Nacional das Associações Atléticas Banco do Brasil. Página oficial. Disponível em: <http://www.fenabb.org.br/>. Acesso em 20/08/2017.

INSTITUTO NATURA. Site institucional. Disponível em: <http://www.institutonatura.org.br>. Acesso em 30/10/2017.

IAS, Instituto Ayrton Senna. Site institucional. Disponível em: <http://institutoayrtonsenna. org.br/pt-br.html>. Acesso em 30/10/2017.

LOPES, F. D; BALDI, M. Redes como perspectiva de análise e como estrutura de governança: uma análise das diferentes contribuições. Revista de Administração Pública. Rio de Janeiro, n. 43, v. 5, set/out, 2009, p. 1007-1035.

MONTAÑO, C. E. O projeto neoliberal de resposta à questão social e a funcionalidade do terceiro setor. Lutas sociais, 2002, p. 1-13.

MPB, Movimento pela Base. Site institucional. Disponível: <http://movimentopelabase.org. br/>. Acesso em 10/04/2018. 
NEWMAN, J.; CLARKE, J. Gerencialismo. Educação e Realidade, Porto Alegre, v. 37, n. 2, p. 353381, maio/ago. 2012.

OECD, Organisation for Economic Co-operation and Development. Principles of Corporate Governance. Paris: OECD, 2015.

OSBORNE, D.; GAEBLER, T. Reinventando o governo; como o espírito empreendedor está transformando o setor público. Brasília: MH Comunicação, 1994.

PERONI, V. M. V. As relações entre o público e o privado nas políticas educacionais no contexto da Terceira Via. Currículo sem Fronteiras, v. 13, n. 2, p. 234-255, maio/ago. 2013a.

Redefinições no papel do Estado: parcerias público-privadas e a democratização da educação. Arquivos Analíticos de Políticas Educativas, v. 21, n. 47, 2013b.

As nebulosas fronteiras entre o público e o privado na educação básica brasileira. Anais... $37^{\text {a }}$ Reunião Nacional da ANPEd. Florianópolis: UFSC, 2015, p. 1-15.

PIRES, D. de O. O histórico da relação público-privado e a formação do Estado Nacional: implicações para a constituição da esfera pública. In: PERONI, Vera Maria V. Diálogos sobre as redefinições do papel do Estado e nas fronteiras entre o público e o privado. São Leopoldo: Oikos, 2015.

PROCOPIUCK, M.; FREY, K. Governança e redes em políticas de caráter público. Anais... ENAPG, Encontro de Administração pública e governança. Salvador/BA, 2008, p. 1-15.

REIS, I. Governança e regulação da educação: Perspectivas e conceitos. Educação, Sociedade \& Culturas, n 39, 2013, p. 101-118.

ROBERTSON, S. A estranha não morte da privatização neoliberal na Estratégia 2020 para a educação do Banco Mundial. Revista Brasileira de Educação, v. 17 n. 50 maio/ago., 2012, p. 283-302.

- VERGER, A. A origem das parcerias público-privada na governança global da educação. Educação e Sociedade, Campinas, v. 33, n. 121, p. 1133-1156, out-dez, 2012.

RS, Rio Grande do Sul. Assembleia Legislativa. Lei no 12.234, de 13 de janeiro de 2005. Dispõe sobre normas para licitação e contratação de parcerias público-privadas, institui o Programa de Parcerias Público-Privadas do Estado do Rio Grande do Sul - PPP/RS - e dá outras providências. Porto Alegre: RS, 2005.

Lei n $^{\circ}$ 12.901, de 11 de janeiro de 2008: Dispõe sobre a qualificação de pessoa jurídica de direito privado como Organização da Sociedade Civil de Interesse Público, institui o Termo de Parceria e dá outras providências. Porto Alegre: RS, 2008.

Lei $\mathbf{n}^{\circ} \mathbf{1 4 . 6 8 6}$, de 22 de janeiro de 2015. Introduz modificações na Lei $n^{\circ}$ 12.234, de 13 de janeiro de 2005, que institui o Programa de Parcerias Público-Privadas do Estado do Rio Grande do Sul - PPP/RS - para incluir a Manifestação de Interesse da Iniciativa Privada e dá outras providências. Porto Alegre: RS, 2015.

SECCHI, L. Modelos organizacionais e reformas da administração pública. RAP, Revista da Administração Pública, n. 43, v. 2, Rio de Janeiro, mar./abril, 2009, p. 347-369. 
SHIROMA, E. O. Redes de políticas públicas e governança da educação: pesquisando a convergência das políticas para docentes nas agendas para a próxima década. Relatório de pesquisa, Florianópolis, UFSC, 2016.

; EVANGELISTA, O. Estado, capital e educação: reflexões sobre hegemonia e redes de governança. Revista Educação e Fronteiras On-Line, Dourados/MS, v.4, n.11, p.21-38, mai./ ago., 2014.

SICREDI, Fundação do Sistema de Crédito Cooperativo. Site institucional. Disponível: <https:// www.sicredi.com.br>. Acesso em 30/10/2017.

TELÓ, F. Fumicultores e entidades de representação política: problemas públicos e engajamento em Santa Cruz do Sul/RS. Contemporânea, v. 6, n. 1, Jan.-Jun., 2016, p. 133-157.

TPE, Todos pela Educação. Site institucional. Disponível: <http://www.todospelaeducacao. org.br>. Acesso em 10/04/2018.

ZANELLA, C. K.; PRIEB, R. I. P. Análise dos interesses articulados ao complexo agroindustrial do fumo a partir dos aportes do direito, ciência política e agricultura sociológica. Revista Sociais \& Humanas, v. 20, n. 2. UFSM, 2007, p. 1-18.

WB, Word Bank. Governance and Development. Washington/D.C, Abril, 1992.

Artigo recebido em: 06/02/2019

Aprovado em: 21/03/2019

\section{Contato para correspondência:}

Maria de Fátima Cóssio. E-mail: cossiofatima13@gmail.com

1 Núcleo de Estudos e Pesquisas em Políticas Educacionais - Universidade Federal de Pelotas.

2 Segundo Montaño (2002), a constituição do terceiro setor exprime as entidades paraestatais e que não integram a administração pública, mas que passam a atuar paralelamente ao Estado na condução das políticas públicas, manifestando-se em diferentes figuras formas (Serviços Sociais Autônomos, Entidades ou Fundações de Apoio, além das OS e OSCIP).

3 "Public sector management, accountability, the legal framework for development, and information and transparency" (WB, 1992, p. 2).

4 "Good governance, for the World Bank, is synonymous with sound development management" (WB, 1992, p. 1). 